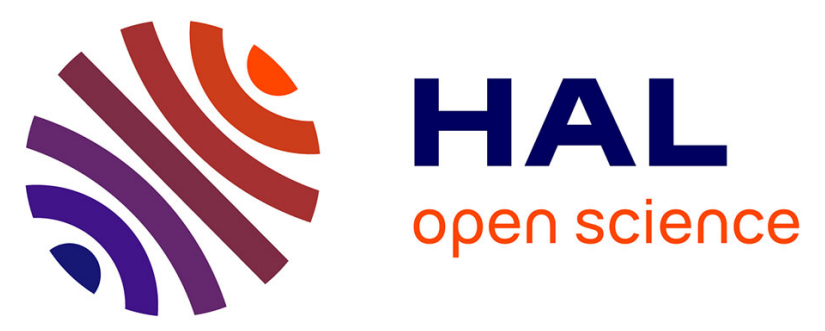

\title{
Chyme reinfusion in patients with intestinal failure due to temporary double enterostomy: a 15-year prospective cohort in a referral centre
}

Denis Picot, Sabrina Layec, Laurence Dussaulx, Florence Trivin, Ronan Thibault

\section{To cite this version:}

Denis Picot, Sabrina Layec, Laurence Dussaulx, Florence Trivin, Ronan Thibault. Chyme reinfusion in patients with intestinal failure due to temporary double enterostomy: a 15-year prospective cohort in a referral centre. Clinical Nutrition, 2017, 36 (2), pp.593-600. 10.1016/j.clnu.2016.04.020 . hal01310456

\section{HAL Id: hal-01310456 \\ https://hal-univ-rennes1.archives-ouvertes.fr/hal-01310456}

Submitted on 21 Jun 2016

HAL is a multi-disciplinary open access archive for the deposit and dissemination of scientific research documents, whether they are published or not. The documents may come from teaching and research institutions in France or abroad, or from public or private research centers.
L'archive ouverte pluridisciplinaire HAL, est destinée au dépôt et à la diffusion de documents scientifiques de niveau recherche, publiés ou non, émanant des établissements d'enseignement et de recherche français ou étrangers, des laboratoires publics ou privés. 


\section{ACCEPTED MANUSCRIPT}

1 Chyme reinfusion in patients with intestinal failure due to temporary double

enterostomy: a 15-year prospective cohort in a referral centre

3

4 Denis Picot, ${ }^{a}$ Sabrina Layec, ${ }^{a}$ Laurence Dussaulx, ${ }^{a}$ Florence Trivin, ${ }^{a}$ Ronan Thibault ${ }^{b}$ 5

6 a Department of Nutritional and Digestive Rehabilitation, Clinique Saint Yves, Rennes, F-

7 35044, France

$8 \quad{ }^{\mathrm{b}}$ Nutrition unit, Department of Endocrinology, Diabetology and Nutrition, Home parenteral

9 nutrition centre, CHU Rennes, Université de Rennes 1, INSERM U991, Rennes, F-35000,

10 France

11

12 Short title: chyme reinfusion and intestinal failure

13

14 Corresponding authors:

15 Dr Denis Picot, MD

16 Nutrition Clinique

17 Clinique Saint Yves

184 rue Adolphe Leray

19 CS 54435

2035044 Rennes Cedex

21 France

22 phone +33299262617 - Fax +33299262584

23 E-mail picot@clinique-styves.fr 
25 Prof. Ronan Thibault, MD, PhD

26 Unité de Nutrition

27 Service d'Endocrinologie-Diabétologie-Nutrition

28 CHU Rennes

29 2, rue Henri Le Guilloux

$30 \quad 35000$ Rennes

31 France

32 Phone +33299289646

$33 \quad$ Fax +33299289647

34 E-mail ronan.thibault@chu-rennes.fr 


\section{Abstract (292 words)}

Background and aims: Patients with double temporary enterostomy may suffer from intestinal failure (IF). Parenteral nutrition (PN) is the gold standard treatment until surgical reestablishment of intestinal continuity. Chyme reinfusion (CR) is a technique consisting in an extracorporeal circulation of the chyme. The aims were to determine: i) whether CR could restore intestinal absorption, decrease PN needs, improve nutritional status and plasma liver tests; ii) the feasibility of home CR.

Methods: From the 232 patients IF consecutively referred for CR from 2000 to 2014, the 212 patients with IF, technical feasibility of CR, and effectively treated by CR, were included. Were collected prospectively before and during CR: daily stomal and fecal outputs, coefficients of nitrogen (CNDA) and fat (CFDA) digestive absorption, weight loss, body mass index (BMI), Nutritional Risk Index (NRI), plasma albumin, citrulline, and liver tests.

Results: 183 patients had temporary double enterostomy and 29 exposed enterocutaneous fistulas. CR reduced the intestinal output (2444 \pm 933 vs $370 \pm 457 \mathrm{ml} /$ day, $\mathrm{P}<0.001$ ), improved CNDA $(46 \pm 16$ vs $80 \pm 14 \%, \mathrm{P}<0.001)$ and CFDA $(48 \pm 25$ vs $86 \pm 11 \%$, $\mathrm{P}<0.001)$, and normalized plasma citrulline concentration $(17.6 \pm 8.4 \mathrm{vs} 30.3 \pm 11.8 \mu \mathrm{mol} / 1$, $\mathrm{P}<0.001)$. PN was stopped in 126/139 (91\%) patients within $2 \pm 8 \mathrm{~d}$. Nutritional status improved $(\mathrm{P}<0.001)$ : weight $(+4.6 \pm 8.6 \%)$, BMI $(+3.8 \pm 7.7 \%)$, plasma albumin $(+6.2 \pm 6.1$ $\mathrm{g} / \mathrm{l})$, and NRI $(+10.9 \pm 9.5)$. The proportion of patients with plasma liver tests abnormalities decreased (88 vs $51 \%, \mathrm{P}<0.01$ ). Home $\mathrm{CR}$ was feasible without any serious complications in selected patients.

Conclusions: CR corrected the intestinal failure by restoring intestinal absorption, allowing PN weaning in $91 \%$ of patients. CR contributes to improve nutritional status and to reduce plasma liver tests abnormalities, and is feasible at home. 


\section{ACCEPTED MANUSCRIPT}

61 Keywords: malnutrition; succus entericus reinfusion; fistuloclysis; parenteral nutrition;

62 ileostomy; enterocutaneous fistula.

63 


\section{Introduction}

In the course of an intestinal surgery procedure, several clinical situations (small bowel resection, peritonitis, fistulae, anastomosis protection...) lead the surgeon to undertake a double temporary enterostomy. The surgical reestablishment of intestinal continuity (SRIC) is usually scheduled at least three months later. In England, the annual incidence of temporary double enterostomy requiring parenteral nutrition (PN) for more than 14 days would be of 18 patients per million [1]. Enterostomy may lead to serious complications, such as acute or chronic dehydration, reported in 18 to $29 \%$ of patients [2,3] and responsible for 40 to $50 \%$ of hospital readmissions [4,5], renal failure [6], electrolyte disturbances, micronutrients and mineral deficiencies, and malnutrition. These complications are responsible for hospital readmissions, increased healthcare-related costs [7] and affect patients' quality of life [8]. Patients with high enterostomy outputs are exposed to intestinal failure (IF) due to type 1 short bowel syndrome (small bowel ended by a terminal stoma without colon in circuit). A small bowel length lower than $100 \mathrm{~cm}$ between the duodeno-jejunal flexure and the stoma mostly leads to intestinal deficiency or IF [9]. ESPEN recommends to define IF as "the reduction of gut function below the minimum necessary for the absorption of macronutrients and/or water and electrolytes, such that intravenous supplementation is required to maintain health and/or growth" [10]. In the setting of temporary double enterostomy, the IF is type 2 according to the ESPEN endorsed recommendations, and defines as a prolonged acute condition, often in metabolically unstable patients, requiring complex multi-disciplinary care and intravenous supplementation over periods of weeks or months [10]. Thus, IF patients with temporary double enterostomy require $\mathrm{PN}$, including home $\mathrm{PN}$, the gold standard therapy until the SIRC. However, PN has its own morbidity and, in the absence of expertise, the risks of infectious, hepatic dysfunction, mechanical and metabolic complications are increased. Chyme reinfusion (CR) is a kind of enteral nutrition technique which reestablishes the small bowel continuity by reinfusing the chyme collected from the afferent, i.e. upstream, small 


\section{ACCEPTED MANUSCRIPT}

90 bowel, in the efferent, i.e. downstream, small bowel through an extracorporeal circulation of

91 the chyme [11]. Small series in adults [12-15] and pediatric patients [16-18] strongly suggest

92 that CR could restore intestinal absorption. This could allow PN interruption only after few

93 days and the improvement of frequent observed liver tests abnormalities [15]. However, the

94 efficacy of CR in patients with temporary double enterostomy waiting for SIRC has never

95 been assessed in larger prospective cohorts including a systematic assessment of intestinal

96 function, PN needs, nutritional status, and plasma liver tests. Moreover the feasibility of home

97 CR has never been assessed. Therefore, the aims of this prospective study were to determine:

98 i) whether CR could restore intestinal absorption, decrease PN needs, improve nutritional

99 status and plasma liver tests; ii) the feasibility of home CR. 


\section{Materials and methods}

102 2.1. Study design

103 This is a prospective observational cohort of the consecutive patients with IF secondary to

104 temporary double enterostomy or entero-cutaneous fistula (ECF) exposed to the abdominal

105 wall, specifically referred for CR to the department of nutritional and digestive rehabilitation

106 at Clinique Saint Yves, Rennes France, from January 2000 to December 2014.

107

108 2.2. Centre description

109 Our 50-bed department is a referral rehabilitation centre for gastrointestinal diseases,

110 including IF, and is staffed with specially trained nurses and nutritionist gastroenterologist

111 physicians. Most patients were referred by the departments of visceral surgery and intensive

112 care of Brittany and West of France. During the five last years, were admitted 120 patients

113 with enterostomy per year, including 20 to $25 \%$ with high stoma outputs who were treated by

114 CR.

\subsection{Inclusion criteria}

117 The inclusion criteria were: IF defined as a theoretical indication to PN, plus a stoma output

118 nihil per mouth of at least $1200 \mathrm{ml} / 24 \mathrm{~h}$; existence of a double enterostomy or at least two

119 orifices of ECF visible on the abdominal wall; theoretical temporary nature of the stoma or

120 ECF in the expectancy of SIRC; presence of efferent small bowel between the stoma and the

121 colon, or a terminal ileostomy; absence of obstruction of digestive fistula between the mouth

122 and the afferent stoma, and in the efferent intestinal tract; ability to catheterize the efferent

123 stoma with a feeding tube on more than $15 \mathrm{~cm}$; absence of progressive peritoneal carcinosis;

124 age $>17$ years; full agreement of the patient to carry out CR and accept the food constraints

125 (the ingested meals must have the consistency of a smooth puree). 
2.4. Data collection

128 The clinical and biological data were collected prospectively and recorded in a specific

129 Access (Microsoft) database registered, as required by the French law, at the French

130 Committee for computing and freedom CNIL $\left(\mathrm{N}^{\circ}\right.$ 1452427). Height was measured at

131 admission and weight twice a week. The enterostomy or fistula output was quantified daily.

132 The biological tests were carried out by the same laboratory. These data were collected for all

133 patients at their admission, before CR was initiated, and repeatedly during CR. Body mass

134 index (BMI) (weight $(\mathrm{kg}) /$ height $\left.(\mathrm{m})^{2}\right)$, weight loss at admission as compared to usual weight

135 (100*(usual weight - actual weight) / usual weight) and Nutritional Risk Index

$136(\mathrm{NRI}=1.519 * \mathrm{Alb}+41.77 *$ weight/usual weight $)$ where Alb is plasma albumin concentration,

137 were calculated. Severe malnutrition risk was defined as NRI $<83.5$, moderate malnutrition

138 risk as $83.5 \leq \mathrm{NRI} \leq 97.5$, and absence of malnutrition risk as $\mathrm{NRI}>97.5$. Plasma values of liver

139 tests, i.e. alanine amino-transferase (ALAT), aspartate amino-transferase (ASAT), alkaline

140 phosphatase (AP), $\gamma$-glutamyl-transpeptidase $(\gamma \mathrm{GT})$, and total bilirubin, higher than two times

141 the normal values (i.e. for total bilirubin $\geq 30 \mu \mathrm{mol} / \mathrm{l}$ ), were considered as increased. Proximal

142 stoma or fecal outputs were daily measured in all patients before and after the initiation of

143 CR, respectively. During CR, anal stools were not daily weighed when their number was

$144 \leq 2 /$ day. Intestinal nitrogen and fat outputs were measured over three consecutive days, before

145 the initiation of CR, and at least three weeks after CR initiation. Nitrogen and fat fecal

146 concentrations were measured according to the Kjeldahl's [19] and the Van de Kamer's [20]

147 methods, respectively. Nitrogen and fat fecal outputs were expressed as the mean daily

148 nitrogen or fat fecal output in g/day. Simultaneously, oral protein and fat intakes were

149 determined using a daily dietary record. Total protein and fat dietary intakes were evaluated

150 by dieticians from: (1) the proportion of food proposed that was consumed $(25 \%, 33 \%, 50 \%$,

$15166 \%, 75 \%, 100 \%$ ); and (2) food composition tables coupled with the software allowing

152 patient's meal choice (Nutriciel_SCJ Informatique, Mont Saint Aignan, France). Nutritional 
food intakes (oral, enteral and parenteral) were expressed as $\mathrm{kcal} / \mathrm{kg}$ actual body weight/day

154 and $\mathrm{g} / \mathrm{kg}$ actual body weight/day for energy and protein, respectively. PN formulas consisted

155 of tricompartimental bags delivering $0.62-1.14 \mathrm{kcal} / \mathrm{ml}$ of energy ( $15-20 \%$ proteins, $29 \%$

156 lipids ( $80 \%$ olive oil, $20 \%$ soy oil), and $51 \%$ carbohydrates). PN formulas came from Baxter,

157 USA. The coefficients of nitrogen (CNDA) and fat (CFDA) digestive absorption, expressed in

158 percentage of ingested protein and fat, represent the proportion of oral nitrogen or fat not

159 recovered in stomial or fecal wet weight, and was calculated as: CNDA $=(1$-(intestinal

160 nitrogen $(\mathrm{g} /$ day $) /$ protein intake $(\mathrm{g} /$ day $) / 6.25) * 100$ and CFDA $=(1-($ steatorrhea $(\mathrm{g} /$ day $) /$ fat

161 intake (g/day) $)^{*} 100$ [21]. Values higher than $85 \%$ were considered as physiological.

162 Fasting plasma citrulline concentration was determined simultaneously with the CNDA and

163 CFDA within the three days before and after CR initiation. Simultaneously, creatinine

164 clearance was calculated with the Cockcroft's formula for $1.73 \mathrm{~m}^{2}$ because alteration of renal

165 function prevents from interpreting plasma citrulline. Plasma citrulline concentration was

166 determined using reverse-phase high performance liquid chromatography (HPLC). As Crenn

167 et al. [22] showed that a plasma citrulline below $20 \mu \mathrm{mol} / 1$ was predictive of IF, we chose this

168 threshold to define a low plasma citrulline.

\subsection{Measurement of small bowel length}

171 The length of the post-duodenal remnant small bowel from the duodeno-jejunal flexure to the

172 proximal stoma was determined by the surgeon during surgery $(97 \%)$ or estimated from X-ray

173 documents obtained by digestive opacification using hydrosoluble contrast (3\%). The

174 downstream small bowel length was measured from the distal stoma to the end of the terminal

175 part of the remnant downstream small bowel, i.e. the ileo-caecal valvula, an ileo-colic

176 anastomosis or a terminal ileostomy (by surgeon $61 \%$, by X-ray opacification $39 \%$ ). The total

177 remnant post-duodenal small bowel length used for the CR was defined as the sum of the

178 upstream and the downstream small bowel lengths. 
2.6. Chyme reinfusion $(\mathrm{CR})$

181 CR consisted in a closed system of extra-corporal circulation of chyme. Continuous CR was performed using the Entéromate ${ }^{\mathrm{TM}}$ II system (Labodial, Les Clayes Sous Bois, France), marketed since 1998 (Figure 1). Entéromate ${ }^{\mathrm{TM}}$ II auto-regulates continuous CR without any adjustment or nurse's intervention, and no uncomfortable odor. The dead space volume of the extra-corporeal circuit is lower than $50 \mathrm{ml}$ and does not cause any volemic deprivation. The tubulures are closed and prevent from outside infectious contamination. The automaton has two peristaltic pumps. One pump works permanently and aspirates the jejunal effluent toward a $30 \mathrm{~mL}$ disposable plastic container, so that the upper stoma pouch is always empty. The weight of the container is continuously and electronically monitored. When the minimal

190 volume of approximately $10 \mathrm{ml}$ is exceeded, the second pump starts and the contents are

191 infused into the diverted downstream small bowel until the return to minimal volume.

192 The downstream small bowel was intubated through the efferent enterostomy with a simple

193 lumen polyurethane naso-gastric tube ch 14-16, Levine-typed, without balloon, into the first

$194 \quad 15-20$ centimeters of the small bowel. A radiologic opacification with water-soluble contrast

195 agents checked the tube position and controlled the anatomy and the length of the downstream

196 small bowel until the colon. During the two days before CR initiation, enteroclysis was

197 initiating by instilling one liter of oral rehydration solution, together with laxatives in case of

198 fecal residues or fecaloma in the colon. At the same time, anti-motility drugs, e.g. loperamide,

199 were stopped to prevent ileus. Antispasmodic agents could be useful in case of abdominal

200 pain, and cholestyramine was given by enteroclysis in the event of diarrhea during the first

201 days. In case of persisting diarrhea, loperamide was used. Antisecretory drugs were used in all 202 patients before and during CR. Octreotide was never used. Once the patient has been 203 adequately trained and is capable of correctly adjusting the rate of reinfusion, portable non204 autoregulated Enteromate Mobile ${ }^{\mathrm{TM}}$ (marketed since 2010 by Labodial, Les Clayes Sous Bois, 
France) pump was used secondly to give autonomy to the patient during the hospitalization and at home. This pump is autonomous thanks to batteries. During CR, patients were mandatorily orally fed ad libitum with puree meals. If the oral intakes seemed insufficient, enteral nutrition was delivered by naso-gastric feeding tube, by gastrostomy, by jejunostomy or by "en Y" enteroclysis in the reinfusion tube in the downstream small bowel. In the cases where oral hydration was insufficient, enteroclysis of additional hydration solutions was used.

\subsection{Definitions}

PN intake was defined as parenteral infusions including administration of nitrogen; otherwise,

214 parenteral infusion was defined as intravenous hydration. The presumed cumulative number

215 of days with saved PN was defined as the number of days between the PN weaning day and

216 the SRIC day, assuming that PN needs would remain stable and PN administered daily until

217 the SRIC day, and was expressed as patients-days and patients-years. The median \pm IQ

218 duration of home CR was defined as the number of days between the CR initiation day and 219 the day before the SRIC day, i.e. the day of CR stop.

\subsection{Statistical analysis}

222 Statistical analyses were performed with XLSTAT 2014 (Addinsoft-SARL). The normality of data distribution was analyzed by the Smirnoff-Kolmogorov test. Categorical variables were compared using the Fisher exact test. According to their normal or non-normal distributions, continuous variables were reported either as mean \pm standard deviation (SD), median \pm interquartile (IQ), and compared between groups using Student's paired t-test or Wilcoxon

227 matched-pairs signed rank test as appropriate. P values equal or less than 0.05 were considered as statistically significant.

\section{Results}


3.1. Patients recruitment and characteristics

232 According to the inclusion criteria, 232 consecutive patients were eligible for CR. Eight (3\%)

233 patients were excluded because CR had to be stopped early because of complications, and 12

234 patients did not match the inclusion criteria. The remaining 212 patients were included

235 (Figure 2). Demographics and aetiology of small bowel resection are summarized in Table 1.

236 Twenty nine (14\%) had entero-parietal fistulae exposed to the abdominal wall, mainly due to

237 peritonitis (44\%) and cancer (34\%). Patients' characteristics did not differ between patients

238 with ECF or enterostomy (data not shown).

3.2. Surgical procedure and subsequent small bowel anatomy

Surgical procedure and subsequent small bowel anatomy is shown in Table 2 . In addition, an additional susmesocolic organ resection (oesophagectomy, gastrectomy, Roux-en-Y gastric bypass, cephalic pancreatectomy) was performed in 15 patients $(7 \%)$.

\subsection{Intestinal absorption (Figure 3)}

CR was associated with a dramatic improvement of intestinal function. CR reduces from 52 to $3 \%(\mathrm{P}<0.0001)$ the proportion of patients with a remnant length of small bowel below 100 $\mathrm{cm}$. The intestinal losses were reduced by $85 \%(\mathrm{P}<0.001)$ and the number of patients with output higher than $1200 \mathrm{ml} / 24 \mathrm{~h}$ decreased from 155 to $9(\mathrm{P}<0.0001)$. CNDA and CFDA were measured before and after CR initiation in 56 and 36 patients, respectively. CNDA, CFDA, and plasma citrulline were measured with a median \pm IQ follow-up of $27 \pm 35$ days (range 10-186 days) after CR initiation. CNDA and CFDA strongly improved with CR (Figure 3).

253 Whereas they were largely below physiological levels before CR, attesting intestinal malabsorption, CNDA and CFDA went back to physiological levels in $47 \%$ and $67 \%$ of patients, respectively $(\mathrm{P}<0.0005)$. The number of patients with plasma citrulline $<20 \mu \mathrm{mol} / 1$ decreased from $47(65 \%)$ to $8(11 \%)(\mathrm{P}<0.0005)(\mathrm{n}=72)$. In eight patients with a creatinine 
clearance $<60 \mathrm{ml} / \mathrm{mn} / 1.73 \mathrm{~m}^{2}$, plasma citrulline was $<20 \mu \mathrm{mol} / \mathrm{l}$ before $\mathrm{CR}$, and plasma

258 citrulline increased after CR in seven patients despite the improvement of renal function.

\subsection{Parenteral nutrition needs}

At admission, within a median ( \pm IQ) time of $33 \pm 25$ days after initial surgery, $139(65 \%)$ patients received PN $(\mathrm{n}=111)$ or IV hydration $(\mathrm{n}=28)$. Despite all patients displayed characteristics of IF and would have to be treated with PN, PN was not initiated in the surgical departments referring the patients. Nevertheless patients with PN at admission had shorter upstream small bowel length, worse intestinal function and lower plasma citrulline than patients who did not receive PN (data not shown). Mean ( \pm SD) energy and protein PN intakes were $24 \pm 9 \mathrm{kcal} / \mathrm{kg} /$ day and $0.9 \pm 0.3 \mathrm{~g} / \mathrm{kg} /$ day respectively, in a mean volume of $2110 \pm 974 \mathrm{ml} /$ day. During CR, mean energy and protein oral intakes were $31 \pm 14$

$\mathrm{kcal} / \mathrm{kg} /$ day and $1.4 \pm 0.7 \mathrm{~g} / \mathrm{kg} /$ day, respectively. An additional enteral nutrition was needed in $72(34 \%)$ patients (“en Y" enteroclysis, $n=46$; nasogastric tube, $n=17$; gastrostomy, $n=7$; jejunostomy, $n=2$ ). The total mean amounts of energy and protein oral and enteral intakes were $36 \pm 14 \mathrm{kcal} / \mathrm{kg} / \mathrm{day}$ and $1.6 \pm 0.7 \mathrm{~g} / \mathrm{kg} /$ day. As a result, $\mathrm{PN}$ and $/$ or IV hydration could 273 be stopped in 126 of 139 patients (91\%), within a median \pm IQ of $2 \pm 9$ days after CR 274 initiation. PN was carried on in 17 patients with a maximum of 186 days. Therefore the median $( \pm$ IQ) time with saved PN was $59 \pm 57$ days per patient. The presumed cumulative median ( \pm IQ) number of days with saved PN was 9723 patients-days (or 26.6 patients-years).

\subsection{Nutritional status}

279 At admission, a majority of patients had one or several criteria of malnutrition (Table 3). CR was associated with the improvement of nutritional status and NRI: mean $( \pm$ SD) weight gain of $4.6 \pm 8.6 \%$, BMI increase of $3.8 \pm 7.7 \%$, plasma albumin of $6.2 \pm 6.1 \mathrm{~g} / \mathrm{L}$, and NRI increase of $10.9 \pm 9.5(\mathrm{P}<0.001$ for all $)$. 
284 3.6. Plasma liver tests

285 At admission, 177 (84\%) patients had one or several abnormal plasma liver tests: ALAT $286(\mathrm{n}=57,27 \%)$, ASAT $(\mathrm{n}=16,8 \%), \operatorname{AP}(\mathrm{n}=96,45 \%), \gamma \mathrm{GT}(\mathrm{n}=170,81 \%)$, and total bilirubin $287(\mathrm{n}=11,6 \%)$.

288 Plasma liver tests (ALAT, ASAT, AP, $\gamma \mathrm{GT}$ ) were performed before and during CR in 155 289 patients, and total bilirubin in 91 patients. With CR, the number of patients who had one or 290 several plasma liver tests abnormalities decreased from 87 to $51 \%(\mathrm{P}<0.001)$ (Figure 4). In addition, only $4 \%$ of patients had liver cholestasis-related jaundice, defined as total bilirubin $\geq 60 \mu \mathrm{mol} / 1$ [23], at admission. In all these patients, CR allowed the normalization of total bilirubin. The prevalence of plasma liver tests abnormalities at admission were compared

294 between the 139 patients who received PN and the 73 who did not. Plasma liver tests values 295 were not significantly different between the two groups (patients with PN vs. without PN, 296 median \pm IQ; ALAT, $44 \pm 65$ vs. $34 \pm 59$ UI/l; ASAT, $32 \pm 35$ vs. $27 \pm 29$ UI/1; $\gamma G T, 175 \pm$ 121 vs. $226 \pm 231 \mathrm{UI} / 1$; AP, $251 \pm 184$ vs. $289 \pm 258 \mathrm{UI} / 1$; total bilirubin, $11 \pm 8$ vs. $10 \pm 8$

$298 \mu \mathrm{mol} / 1)$, and the percentage of patients with at least one abnormal value (79 vs. 86\%) as well. 299 These findings suggest that PN is not the direct cause of plasma liver tests abnormalities in IF 300 patients with temporary double enterostomy.

\subsection{Feasibility of home chyme reinfusion}

303 In 59 (28\%) patients (37 males), CR was feasible at home in selected patients after specific training and education. At admission, these patients were significantly younger ( $53 \pm 15 \mathrm{vs}$ $64 \pm 14$ years, $\mathrm{P}<0.001)$, with lower BMI (21 \pm 4 vs. $23 \pm 5, \mathrm{P}<0.002)$, upper plasma albumin $306(30.4 \pm 6.2$ vs. $27.6 \pm 6.4 \mathrm{~g} / 1, \mathrm{P}<0.01)$, but without any difference in the proportion of patients

307 with nutritional risk assessed by NRI. The upstream small bowel length was longer (138 \pm 67 308 vs. $110 \pm 71 \mathrm{~cm}, \mathrm{P}=0.05)$ and the proportion of patients with an upper small bowel length 
$<100 \mathrm{~cm}$ was lower (32 vs. $56 \%, \mathrm{P}=0.025$ ). The median $( \pm \mathrm{IQ})$ follow up of $\mathrm{CR}$ from its

310 initiation to the SRIC was $63 \pm 51$ days. The median ( \pm IQ) duration of hospital stay after CR

311 initiation was $22 \pm 14$ days with a median duration of home CR of $36 \pm 40$ days, accumulating

3122697 patients-days or 7.4 patients-years. Fifteen patients (25\%) received home CR for more

313 than two months (maximum 170 days). Nine hospital readmissions of eight patients for minor

314 problems were reported, lasting six to ten days. No patient had to stop CR.

\section{4. Discussion}

317 To our knowledge, is reported here the largest cohort of CR performed in IF patients with

318 temporary double enterostomy or ECF and waiting for SRIC. Our study clearly shows that

319 CR corrected the IF by restoring intestinal absorption, allowing quick PN weaning in 91\% of

320 patients. CR contributes to improve nutritional status and to reduce plasma liver tests

321 abnormalities. In addition, the study reports for the first time the feasibility of home CR.

322 Our results confirm those of small series in adults [12-15]. The interruption of the small

323 intestine by a double enterostomy or an ECF separates the small bowel into an upstream

324 afferent segment, with impaired digestive and absorptive function, and a downstream efferent

325 segment, totally deprived of digestive secretions, bowel flow and succus entericus. This leads

326 to IF since the upstream segment insufficiently absorbs macronutrients, micronutrients,

327 minerals, water, electrolytes, and biliary salts, the latter resulting in enterohepatic cycles

328 disruption. CR artificially re-establishes the digestive function by an extra-corporeal circuit.

329 The chyme collected from the upstream small bowel segment is permanently reinfused via the

330 enterostomy into the diverted distal small bowel segment. One supposed mechanism of CR-

331 induced improvement of intestinal function is the restoration of the ileal brake $[24,25]$. CR

332 differs from fistuloclysis in which enteral nutrition is instilled in the downstream intestine

333 without any reinfusion of the upstream stoma outputs [26]. In our experience, in case of 
insufficient food intake during $\mathrm{CR}$, enteral nutrition could be administered classically through

335 a nasogastric tube, or in some cases, by fistuloclysis.

336 Although first described in 1977 by Etienne Levy, and recently suggested as an alternative therapy in IF patients [10], CR is rarely used, under recognized, and not endorsed, as in France, by most health insurances. At this time, PN remains the gold standard therapy for IF patients with temporary double enterostomy, until the patients underwent the SRIC, i.e. within

340 a minimal duration of three months. The PN and catheter-related complications are well

341 known [27] and their frequency is more important when the patient is not managed by an expertise centre, which is the most frequent situation. PN costs are much higher than those of

343 enteral nutrition and increase with complications [28]. In this study, the presumed cumulative

344 number of days with saved PN could reach of maximal value of almost 10'000 patients-days,

345 i.e. 27 patients-years. In UK, Saunders [7] evaluated the minimal median costs of 25 type 2 IF

346 patients' therapies as: 56'400€ of initial costs, 4'522€ of hospital readmissions costs, 25'892

$347 €$ of SRIC costs, i.e. 520,551 and $855 € /$ patient/day, respectively. For this author, a great part

348 of the costs resulted from PN-related complications. Therefore, by allowing the PN weaning

349 within a short period, CR could be associated with substantial cost-savings. The prospective

350 randomized controlled trial FRY, supported by the French National Clinical Research

351 Program, will determine the impact of CR compared to PN on the incidence of complications,

352 healthcare costs and quality of life in IF patients with temporary high-output double

353 enterostomy.

354 One considerable advantage of CR is, by using the whole remnant small bowel, to prefigure

355 the post-SRIC intestinal function. Indeed some symptoms occurring during CR, such as pain,

356 fecal incontinence, diarrhea, would have occurred after SRIC. Thus CR should allow

357 anticipating and even preventing situations that would have occurred after the SRIC with

358 potentially more serious consequences. In the presented study, eight patients were excluded

359 because of CR early complications, including one lethal. In the other cases, CR allows 
tailoring the surgical strategy or initiating preoperative specific therapy, such as anal

361 biofeedback for fecal incontinence. Besides these advantages, CR has some inconveniences.

362 The main inconvenience of CR is the permanent obligation for the patients to eat a smooth texture food to avoid tubes obstruction. This could affect quality of life. Also CR is not

364 adapted to most university or general hospitals which are dedicated to acute diseases and

365 where the hospital length of stay must be as short as possible. Indeed CR should be integrated

366 in a global approach of intestinal rehabilitation. Patients require complex management of

367 opened abdominal wounds, high intestinal outputs and need a multi-disciplinary nutrition

368 team during the minimal three months period before the SRIC. Our centre is dedicated to

369 intestinal rehabilitation. We strongly believe that such centres should be developed worldwide

370 to improve the management of IF patients.

371 This study shows for the first time that CR is feasible at home. For this purpose, dedicated

372 portable pumps were developed. Unfortunately, home CR is not yet recognized by French

373 health insurances as a nutrition support technique, needing us selecting only the most

374 specifically trained and educated patients ( $28 \%$ of the cohort), who have thus acquired total

375 autonomy for CR and basic stoma care. For home CR, a dedicated clinical pathway was

376 elaborated including a thesaurus of solutions facing well defined technical problems. As a

377 result, none of the patients were discouraged to return home, only a few were readmitted for

378 minor problems, and none had to go back to PN. More studies are needed including a greater

379 number of patients and centres to demonstrate that home CR is definitively safe and beneficial

380 for IF patients with temporary double enterostomy awaiting for SRIC.

381 Plasma liver tests abnormalities, mostly cholestatic liver disease, have been reported with a

382 prevalence of 28 to $65 \%$ of PN-treated IF patients [29]. At admission, plasma liver tests

383 abnormalities were not significantly more prevalent in patients with PN compared to those

384 without, suggesting that PN does not explain alone plasma liver tests abnormalities. Small

385 bowel bacterial overgrowth is one cause of liver damage. In the diverted downstream small 
387 adherence of bacteria to the intestinal epithelium and release of bacterial toxins can promote 388 bacterial translocation to the liver [30]. In the upstream small bowel, bacterial overgrowth is 389 facilitated by the profusion of unabsorbed nutrients, and the use of antimotility drugs and 390 proton pump inhibitors. The endoluminal production of alcohol and acetaldehyde in the

391 intestinal lumen and in the hepatocytes could also explain in part the plasma liver tests

392 abnormalities [31,32]. Another presumed mechanism is the disruption of entero-hepatic

393 cycles, especially bile salts malabsorption. When entero-hepatic cycles are restored by the

394 SRIC or CR reestablishment of intestinal continuity, plasma liver tests normalized in adults

395 [13] and children [18]. Their improvement seems greater in patients treated by fistuloclysis

396 coupled with succus entericus reinfusion than by fistuloclysis alone [25]. Bile salts are potent

397 signaling molecules, and at physiological state, activate an intracellular bile salt receptor FXR

398 during transcellular passage of the small intestinal and hepatic epithelium [33]. Bile salts-

399 induced FXR activation is in part mediated by endocrine-acting fibroblast growth factor

400 (FGF) 19, a bile salt-induced enterokine. The release of the FGF19 subsequently inhibits bile

401 salt synthesis from cholesterol. In case of IF-induced enterohepatic cycle disruption, bile salts

402 synthesis is not inhibited, resulting in overproduction and liver accumulation that could have a

403 direct toxicity on hepatocytes. CR could act by restoring bile salts enterohepatic cycle and

404 bile salts signalling, decreasing liver inflammation and plasma liver tests. A study is ongoing

405 to demonstrate this hypothesis. Our study has some limitations. The prevalence of CR-related

406 technical problems (e.g. tube disinsertions, chyme leaks, stoma care problems,...) and

407 gastrointestinal side effects were not collected. Their management requires dedicated

408 healthcare staff education. The patients' quality of life was not assessed whereas the

409 permanent obligation of smooth texture food could have affected it. The data collection was

410 prospective but not performed at predefined endpoints after CR initiation. However it has

411 unlikely affected the main findings since data were collected in the three weeks before SRIC, 


\section{ACCEPTED MANUSCRIPT}

412 at a time when CR did not further improve intestinal function or plasma liver tests values.

413 Finally, as we could not identify the patients who could have received PN during their stay in

414 the surgical departments (where was performed the initial surgery) in whom PN could have

415 been stopped within the few days before admission at Clinique St Yves, our study could not

416 exclude beneficial effects of PN in the early phase.

417

418 5. Conclusions

419 In case of IF secondary to high output temporary enterostomy, CR is an efficient and reliable

420 technique of enteral nutrition which corrects IF by restoring intestinal absorption, allowing

421 PN weaning in $91 \%$ of patients. CR contributes to improve nutritional status and to reduce

422 plasma liver tests abnormalities, and is feasible at home in well selected patients. Our study

423 should improve the awareness of intensivists, digestive surgeons and gastroenterologists

424 involved in IF management to spread the use of CR. 


\section{Acknowledgements}

427 We are indebted to all the staff of the Department of Nutritional and Digestive Rehabilitation,

428 Clinique Saint Yves, Rennes, France, to prof. C. Bendavid and Dr A. Tas (Laboratoire de

429 Biochimie Générale, Hôpital Pontchaillou, CHU de Rennes) for the technical support

430 allowing the completion of this study, and to Mrs Nathalie Voisin for her help in manuscript

431 drafting.

432

433 Statement of authorship

434 DP designed the study, carried out the collection of data, performed the statistical analyses,

435 and drafted the manuscript. SL carried out the collection of data, and drafted the manuscript.

436 LG carried out the collection of data. FT carried out the collection of data. RT designed the

437 study, performed the statistical analyses, and drafted the manuscript.

438

\section{Conflict of interest statement}

440 DP declares advisory activities without any financial retribution with Labodial. SL, LD, FT

441 and RT declare no conflict of interest regarding this study. 


\section{References}

446 [1] Strategic Framework for Intestinal Failure and Home Parenteral Nutrition Services for 447 Adults in England. Implementation Plan 2009

448 http://www.webarchive.org.uk/wayback/archive/20130328001800/http://www.specialisedserv 449 ices.nhs.uk/library/28/Strategic_Framework_for_Intestinal_Failure_and_Home_Parenteral_N 450 utrition_Services_for_Adults_in_England.pdf

451 [2] Paquette IM, Solan P, Rafferty JF, Ferguson MA, Davis BR. Readmission for dehydration 452 or renal failure after ileostomy creation. Dis Colon Rectum 2013;56:974-979

453 [3] Åkesson O, Syk I, Lindmark G, Buchwald P. Morbidity related to defunctioning loop 454 ileostomy in low anterior resection. Int J Colorectal Dis 2012;27:1619-1623

455 [4] Messaris E, Sehgal R, Deiling S, Koltun WA, Stewart D, McKenna K et al. Dehydration 456 Is the Most Common Indication for Readmission After Diverting Ileostomy Creation. Dis 457 Colon Rectum 2012;55:175-180

458 [5] Hayden DM, Pinzon MC, Francescatti AB, Edquist SC, Malczewski MR, Jolley JM et al. 459 Hospital readmission for fluid and electrolyte abnormalities following ileostomy construction: 460 preventable or unpredictable? J Gastrointest Surg 2013;17:298-303

461 [6] Jafari MD, Halabi WJ, Jafari F, Nguyen VQ, Stamos MJ, Carmichael JC et al. Morbidity 462 of diverting ileostomy for rectal cancer: analysis of the american college of surgeons national 463 surgical quality improvement program. Am Surg 2013;79:1034-1039

464 [7] Saunders J, Parsons C, King A, Stroud M, Smith T. The financial cost of managing 465 patients with type 2 intestinal failure; experience from a regional centre. e-SPEN Journal $466 \quad 2013 ; 8: \mathrm{e} 80-\mathrm{e} 85$

467 [8] Dibb M, Teubner A, Theis V, Shaffer J, Lal S. Review article: the management of longterm parenteral nutrition. Aliment Pharmacol Ther 2013;37:587-603 


\section{ACCEPTED MANUSCRIPT}

[9] Tappenden KA. Pathophysiology of short bowel syndrome: considerations of resected and residual anatomy. JPEN 2014;38:14S-22S

[10] Pironi L, Arends J, Baxter J, Bozzetti F, Peláez RB, Cuerda C et al. The Home Artificial

Nutrition \& Chronic Intestinal Failure and the Acute Intestinal Failure Special Interest Groups

of ESPEN. ESPEN endorsed recommendations. Definition and classification of intestinal

474 failure in adults. Clin Nutr 2015;34:171-180

475 [11] Levy E, Frileux P, Cugnenc PH, Honiger J, Ollivier JM, Parc R. High-output external

476 fistulae of the small bowel: management with continuous enteral nutrition. Br J Surg $1989 ; 76: 676-679$

[12] Calicis B, Parc Y, Caplin S, Frileux P, DehniI N, Ollivier JM et al. Treatment of

postoperative peritonitis of small-bowel origin with continuous enteral nutrition and succus entericus reinfusion. Arch Surg 2002;137:296-300

[13] Rinsema W, Gouma DJ, von Meyenfeldt MF, Soeters PB. Reinfusion of secretions from high-output proximal stomas or fistulas. Surg Gynecol Obstet 1988;167:372-376

[14] Pflug AM, Utiyama EM, Fontes B, Faro M, Rassian S. Continuous reinfusion of succus entericus associated with fistuloclysis in the management of a complex jejunal fistula on the abdominal wall. Int J Case Rep 2013;4:716-718

486 [15] Picot D, Garin L, Trivin F, Kossovsky MP, Darmaun D, Thibault R. Plasma citrulline is a marker of absorptive small bowel length in patients with transient enterostomy and acute intestinal failure. Clin Nutr 2010;29:235-242

[16] Drenckpohl D, Vegunta R, Knaub L, Holterman M, Wang H, Macwan K et al.

490 Reinfusion of Succus Entericus Into the Mucous Fistula Decreases Dependence on Parenteral

491 Nutrition in Neonates. ICAN: Infant, Child, \& Adolescent Nutrition 2012;4:168-174

492 [17] Richardson L, Banerjee S, Rabe H. What Is the Evidence on the Practice of Mucous

493 Fistula Refeeding in Neonates With Short Bowel Syndrome? J Pediatr Gastr Nutr

$494 \quad 2006 ; 43: 267-270$ 


\section{ACCEPTED MANUSCRIPT}

[18] Schäfer K, Schledt A, Schiedtl A, Linderkamp O, Gfrörer S, Roth H. Decrease of

496 cholestasis under continuous extracorporeal stool transport (CEST) in prematures and

497 neonates with stomas. Eur J Pediatr Surg 2000;10:224-227

498 [19] Kjeldhal J. A new method for the determination of nitrogen in organic substances.

499 Zeitschrist für Analystische. Chemie 1883;22:366

500 [20] Van de Kamer JH, Ten Bokkel Huinink H, Weyers HA. Rapid method for the

501 determination of fat in feces. J Biol Chem 1949;177:347-55

502 [21] Layec S, Beyer L, Corcos O, Alves A, Dray X, Amiot A, et al. Increased intestinal 503 absorption by segmental reversal of the small bowel in adult patients with short-bowel

504 syndrome: a case-control study. Am J Clin Nutr 2013;97:100-108

505 [22] Crenn P, C. Coudray-Lucas C, Thuillier F, Cynober L, Messing B. Postabsorptive

506 plasma citrulline concentration is a marker of absorptive enterocyte mass and intestinal failure

507 in humans. Gastroenterology 2000;119:1496-1505

508 [23] Cavicchi M, Beau P, Crenn P, Degott C, Messing B. Prevalence of liver disease and

509 contributing factors in patients receiving home parenteral nutrition for permanent intestinal

510 failure. Ann Intern Med 2000;132:525-32

511 [24] Lévy E, Palmer DL, Frileux P, Parc R, Huguet C, Loygue J. Inhibition of upper

512 reinfusion of succus entericus into the distal small bowel: a clinical study of 30 patients with

513 peritonitis and temporary enterostomy. Ann Surg 1983;198:596-600

514 [25] Wu Y, Ren J, Wang G, Zhou B, Ding C, Gu G et al. Fistuloclysis improves liver function

515 and nutritional status inpatients with high-output upper enteric fistula. Gastroenterol Res Pract

$516 \quad 2014 ; 2014: 941514$

517 [26] Teubner A,K. Morrison K, Ravishankar HR, Anderson ID, Scott NA, Carlson GL.

518 Fistuloclysis can successfully replace parenteral feeding in the nutritional support of patients

519 with enterocutaneous fistula. Br J Surg 2004;91:625-631 
520 [27] Dreesen M, Foulon V, Spriet I, Goossens GA, Hiele M, De Pourcq L et al.

521 Epidemiology of catheter-related infections in adult patients receiving home parenteral

522 nutrition: a systematic review. Clin Nutr 2013;32:16-26

523 [28] Winkler MF, Smith CE. Clinical, social, and economic impacts of home parenteral

524 nutrition dependence in short bowel syndrome. JPEN 2014;38(Suppl 1):32S-37S

525 [29] Shaffer JL. Hepatic complications of parenteral nutrition. Clin Nutr 1995;14 (Suppl

$526 \quad 1): 59-64$

527 [30] Kumpf VJ. Pharmacologic management of diarrhea in patients with short bowel 528 syndrome. JPEN 2014;38(1 Suppl):38S-44S

529 [31] Picot D, Lauvin R, Hellegouarc'h R. Intra-digestive fermentation in intestinal

530 malabsorption syndromes: relations with elevated serum activity of gammaglutamyl-

531 transpeptidase. Gastroenterol Clin Biol 1997;21:562-566

532 [32] Zhu L, Baker SS, Gill C, Liu W, Alkhouri R, Baker RD, et al. Characterization of gut

533 microbiomes in nonalcoholic steatohepatitis (NASH) patients: a connection between

534 endogenous alcohol and NASH. Hepatology 2013;57:601-609

535 [33] Schaap FG, Trauner M, Jansen PL. Bile acid receptors as targets for drug development.

536 Nat Rev Gastroenterol Hepatol 2014;11:55-67 
ACCEPTED MANUSCRIPT

538 Table 1- Patients' demographics and aetiology of small bowel resection $(n=212)$.

\begin{tabular}{|c|l|}
\hline Male / female $-\mathrm{n}$ & $125 / 87$ \\
\hline Age - mean \pm SD (range) & $61.4 \pm 14.8(17-90)$ \\
\hline $\begin{array}{c}\text { Aetiology of small bowel resection }-\mathrm{n}(\%) \\
\text { Cancer }\end{array}$ & $63(30)$ \\
\hline Radiation enteritis & $9(4)$ \\
\hline Mechanical occlusion & $43(20)$ \\
\hline Ischaemia & $40(19)$ \\
\hline Peritonitis & $36(17)$ \\
\hline Inflammatory bowel diseases & $14(7)$ \\
\hline Trauma & $7(3)$ \\
\hline
\end{tabular}

SD, standard deviation. 
540 Table 2- Surgical procedure and subsequent small bowel anatomy at admission.

541

\begin{tabular}{|c|c|}
\hline Fistulae $-\mathrm{n}(\%)$ & $29(14)$ \\
\hline Jejuno-parietal & 22 \\
\hline Ileo-parietal & 7 \\
\hline Enterostomy $-\mathrm{n}(\%)$ & $183(86)$ \\
\hline Loop stomy & $45(24)$ \\
\hline Double end-loop stomy & $113(62)$ \\
\hline Separated double end stomy & $25(14)$ \\
\hline SB resection $\geq 30 \mathrm{~cm}-\mathrm{n}(\%)$ & $147(69)$ \\
\hline Resection SB length $(\mathrm{cm})(\mathrm{n}=147)^{\S}$ & $62 \pm 62$ \\
\hline Afferent SB length $(\mathrm{cm})(\mathrm{n}=159)^{\S}$ & $100 \pm 90$ \\
\hline Afferent SB length $<100 \mathrm{~cm}-\mathrm{n}(\%)$ & $83(52)$ \\
\hline Efferent SB length $(\mathrm{cm})(\mathrm{n}=161)^{\S}$ & $100 \pm 100$ \\
\hline Total SB length $(\mathrm{cm})(\mathrm{n}=125)^{\S}$ & $220 \pm 95$ \\
\hline Total SB length $<100 \mathrm{~cm}-\mathrm{n}(\%)$ & $4(3)$ \\
\hline Downstream SB anatomy $-\mathrm{n}(\%)$ & $161(76)$ \\
\hline Ileo-colon & $24(12)$ \\
\hline Terminal ileostomy & $5(2)$ \\
\hline Ileo-rectal anastomosis & $22(10)$ \\
\hline Terminal colostomy & \\
\hline
\end{tabular}

${ }^{\S}$ median \pm interquartiles. SB, small bowel 
ACCEPTED MANUSCRIPT

544 Table 3- Evolution of nutritional status between admission (before CR initiation) and 545 discharge (after CR) $(\mathbf{n}=\mathbf{1 6 6})$.

546

547

548

549

550

551

552

\begin{tabular}{|l|l|l|l|}
\hline Parameters & Before CR & After CR & P value \\
\hline Weight loss $(\%)^{\#}$ & $13.3 \pm 9.8(9-47)$ & $9.7 \pm 9.1(20-42)$ & $<0.001$ \\
\hline Body mass index ${ }^{\#}$ & $23.0 \pm 5.2(13.6-47.9)$ & $23.8 \pm 4.5(14.9-44.9)$ & $<0.001$ \\
\hline Plasma albumin $(\mathrm{g} /)^{\#}$ & $27.7 \pm 6.6(11.4-46.1)$ & $33.9 \pm 5.1(18.3-44.8)$ & $<0.001$ \\
\hline Plasma albumin $<30 \mathrm{~g} / 1$ & $108(65)$ & $41(25)$ & $<0.001$ \\
\hline NRI $^{\#}$ & $78.3 \pm 10.9(47-108)$ & $89.2 \pm 8.9(60-113)$ & $<0.001$ \\
\hline \multicolumn{1}{|c|}{ NRI $<83.5$} & $115(69)$ & $37(22)$ & \\
\hline \multicolumn{1}{|c|}{$83.5 \leq \mathrm{NRI} \leq 97.5$} & $44(27)$ & $103(62)$ & $<0.001$ \\
\hline NRI $>97.5$ & $7(4)$ & $26(16)$ & \\
\hline
\end{tabular}

Results are expressed as $\mathrm{n}(\%)$, except ${ }^{\#}$ mean \pm standard deviation (range). Nutritional risk index (NRI) is calculated as: $1.519 *$ plasma Albumin $+41.77 *$ weight/usual weight.

Malnutrition risk could be categorised as severe $(\mathrm{NRI}<83.5)$, moderate $83.5 \leq \mathrm{NRI} \leq 97.5$ and low (NRI>97.5). 
Figure legends

\section{ACCEPTED MANUSCRIPT}

554

555 Figure 1- Chyme reinfusion technique with the automated pump Enteromate II $^{\circledR}$

556 (Labodial, Clayes-sous-Bois, France). The left pump works permanently and aspirates the

557 jejunal effluent from the afferent stoma toward a $30 \mathrm{ml}$ disposable plastic container, which is

558 hung on an electronic steelyard. The upper stoma pouch is always empty. The weight of the

559 container is continuously and electronically monitored. When the minimal volume of

560 approximately $10 \mathrm{ml}$ is exceeded, the second pump starts and the contents are infused into the diverted downstream small bowel until the return to minimal volume.

Figure 2- Study flow chart.

Figure 3- Effects of chyme reinfusion (CR) on intestinal absorption measured before CR initiation (left boxes) and at discharge (right boxes). Stomal (before CR) and fecal outputs (during CR) are expressed as $\mathrm{dl} / 24 \mathrm{~h}$. Coefficients of nitrogen digestive absorption (CNDA) = (1-(intestinal nitrogen/ nitrogen intake))*100. Coefficient of fat digestive absorption (CFDA) $=(1$-(intestinal lipids/lipid intake) $) * 100$. Values are presented as mean (square points), SD (vertical solid bars), quartile 2 and 3 (shaded squares), median (horizontal bar in the shaded squares), extremes (vertical dashed bars). n, number of patients measured twice: before CR and at discharge. $* * * \mathrm{P}<0.001$.

574 Figure 4- Evolution of the percentage of patients with plasma liver tests abnormalities

575 defined as higher than two times the normal values between admission (before CR initiation) and discharge (after CR initiation) (n=155 for ALAT, ASAT, $\gamma$ GT, AP; n=91

577 for total bilirubin). ALAT, alanine amino-transferase; AP, alkaline phosphatase; ASAT, 


\section{ACCEPTED MANUSCRIPT}

578 aspartate amino-transferase; $\gamma \mathrm{GT}$, gamma-glutamyl-transpeptidase; $\mathrm{TB}$, total bilirubin.

579

${ }^{* * *} \mathrm{P}<0.001$.

580 
Figure 1

582

583

584

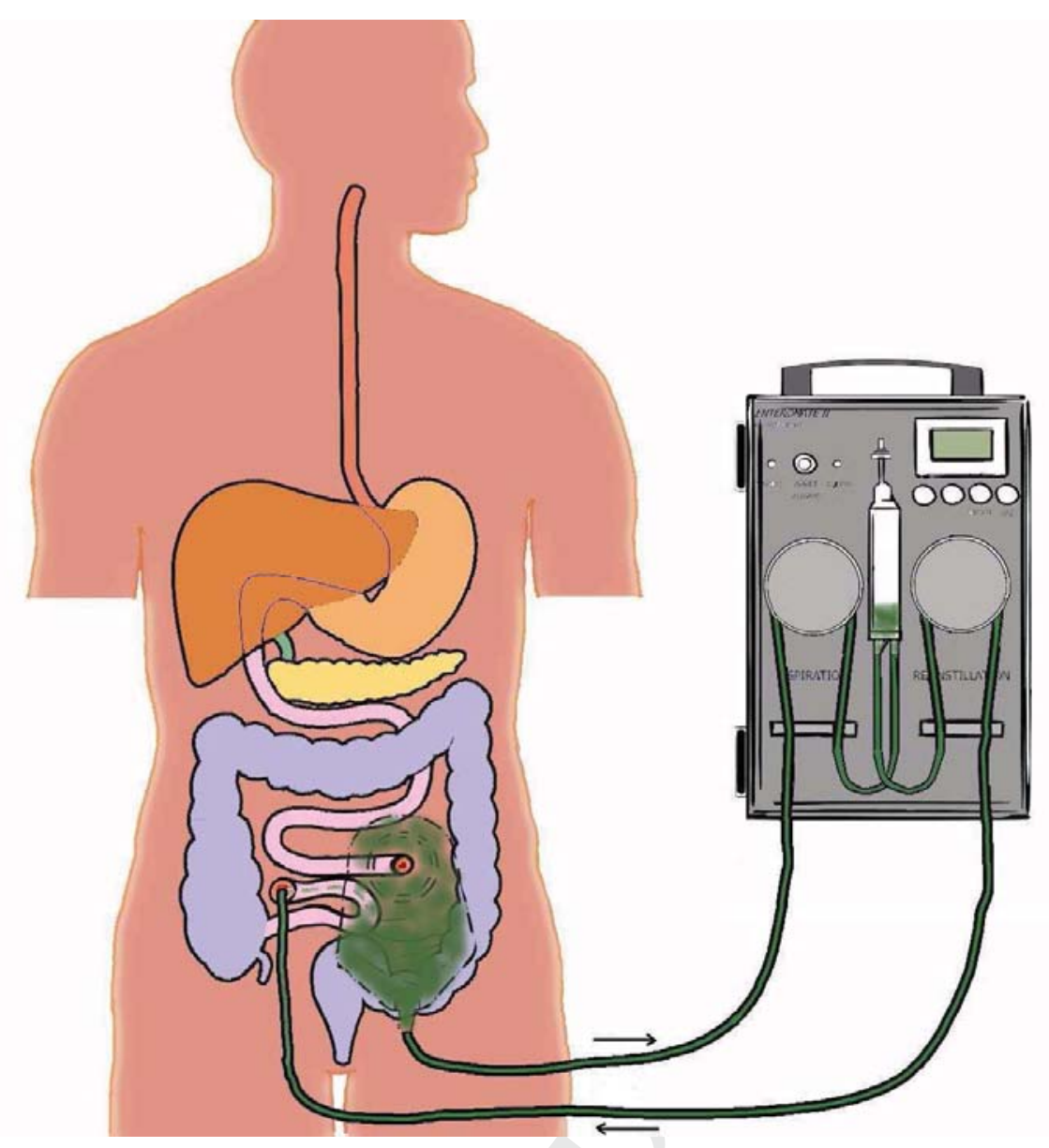

585 
601

602

603

604

605

606
Figure 2

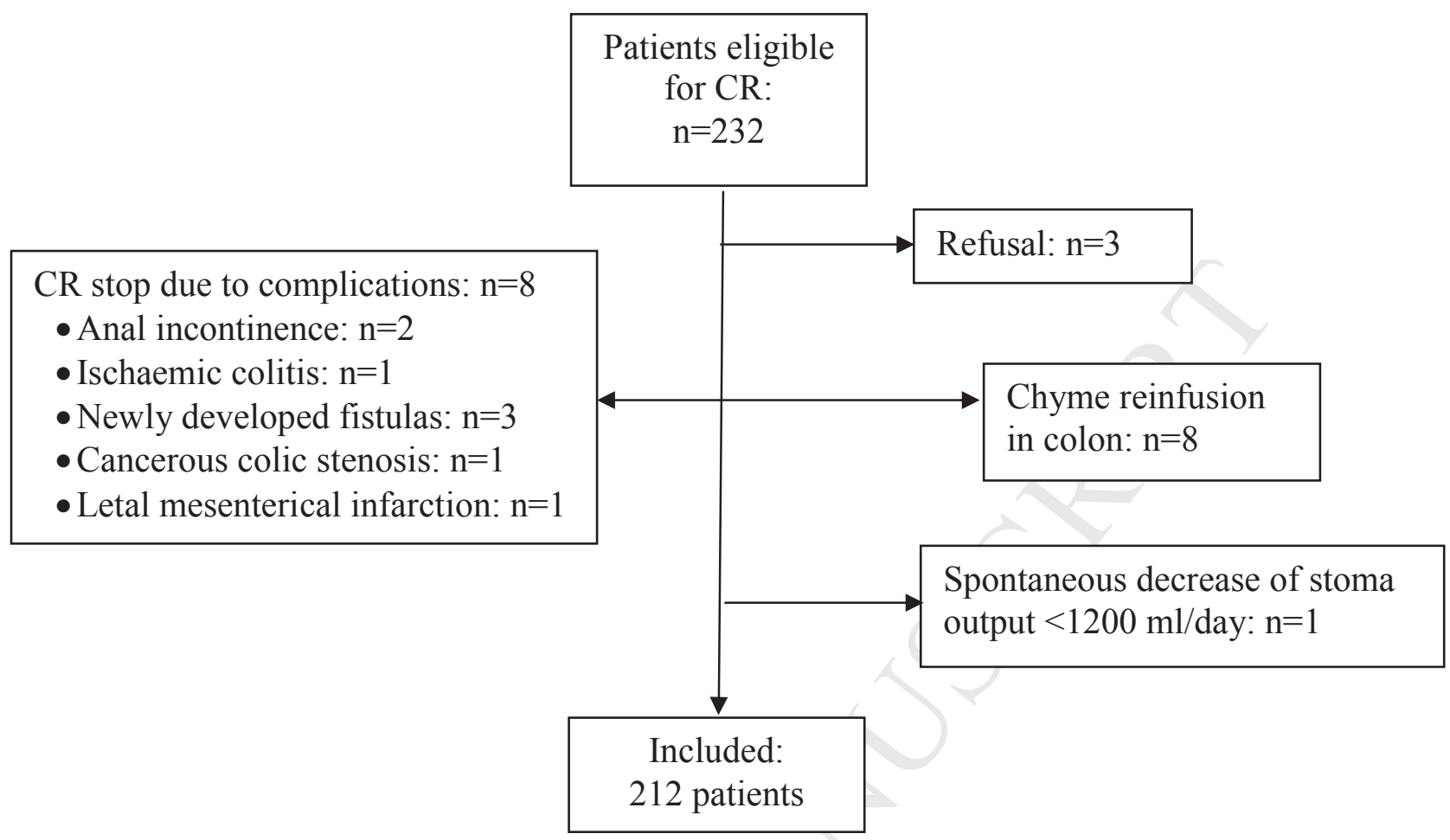


607

608

609

\section{ACCEPTED MANUSCRIPT}

Figure 3

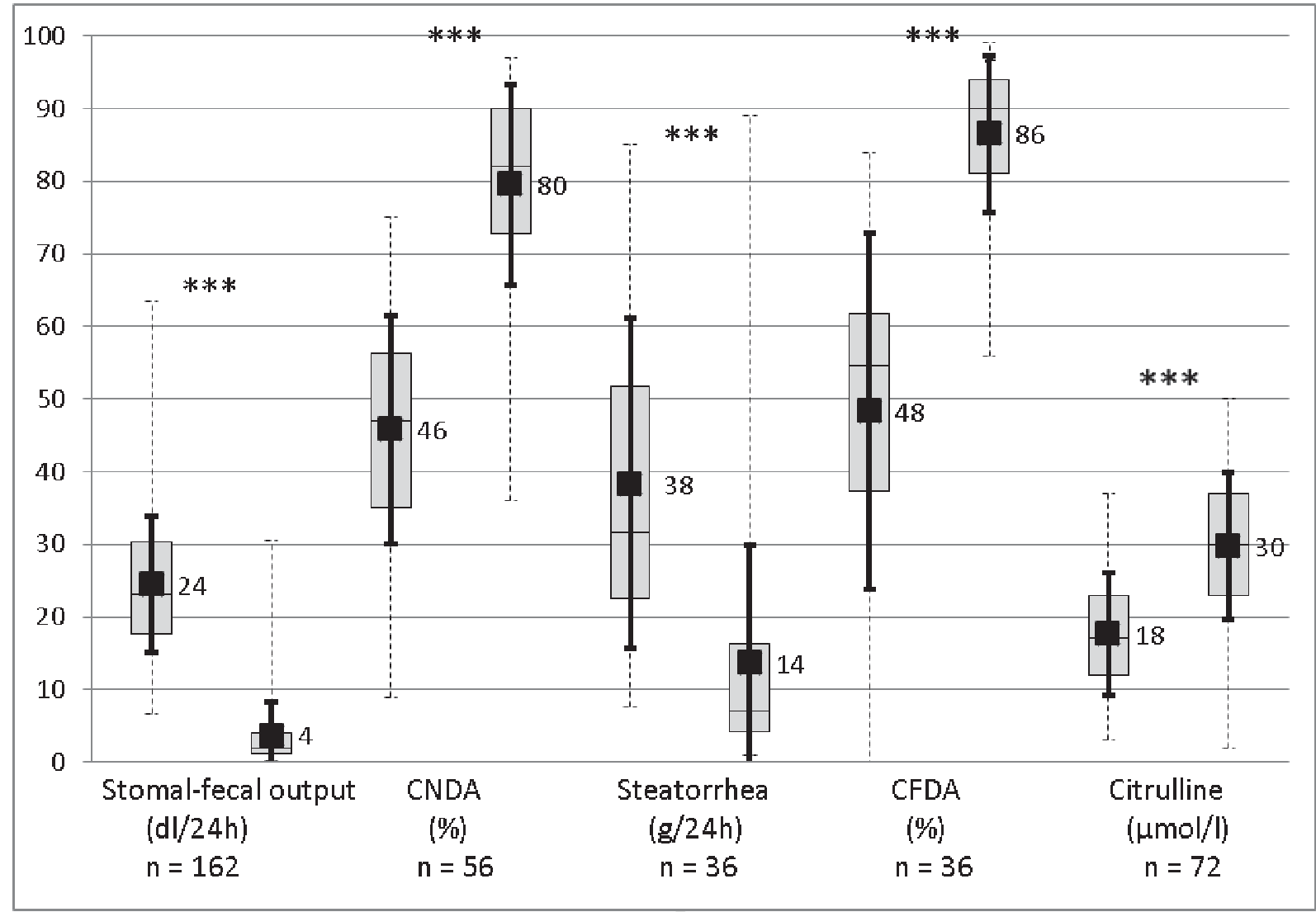


610

611

Figure 4

612

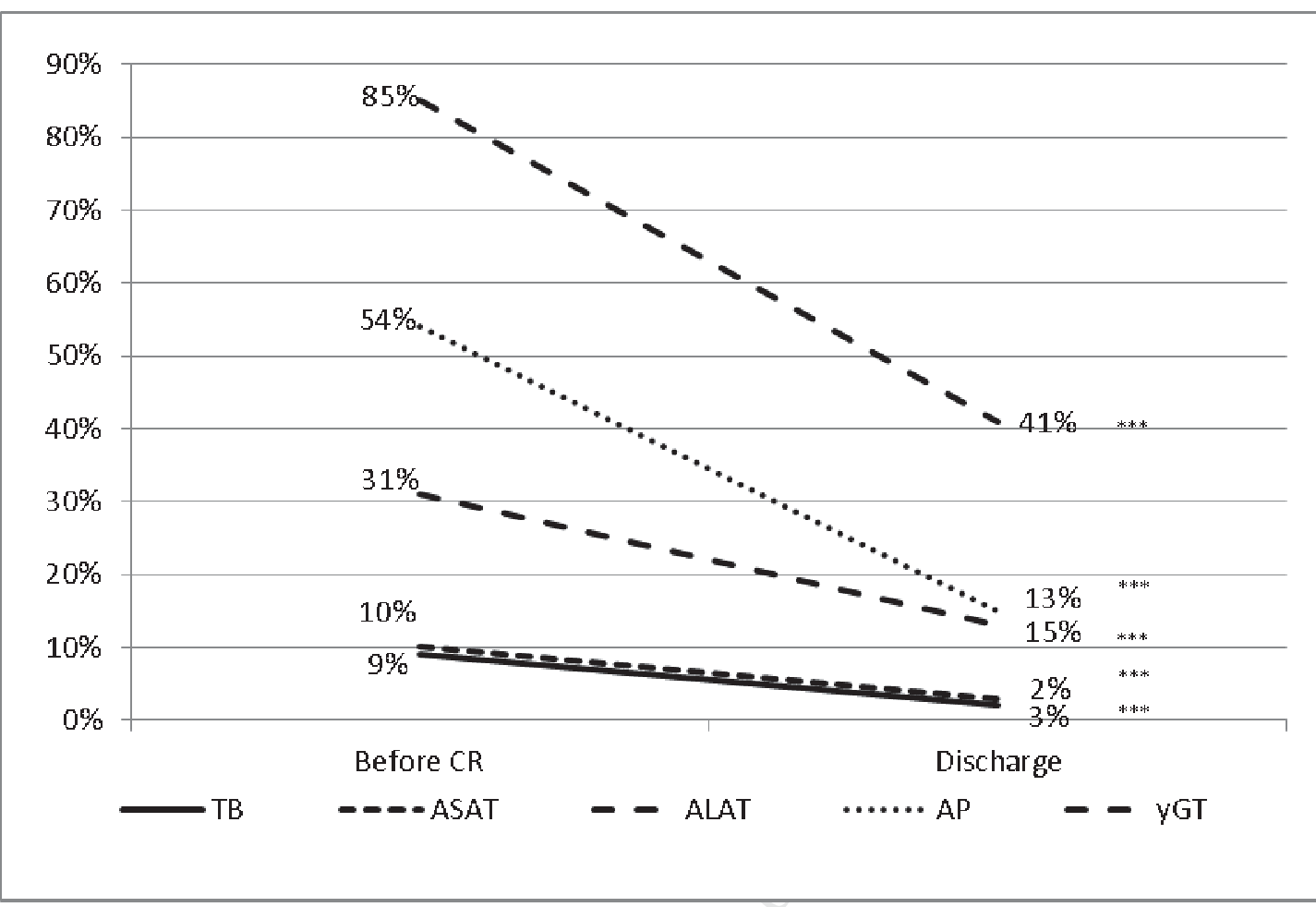

613 